Running head: 3 Prosocial Skills According to Gender and Status

Spencer, K. A., Bull, R., Betts, L. R., \&Winder, B. (in press). Gender differences in theory of mind, empathic understanding, and moral reasoning in an offending and a matched nonoffending population. International Journal of Offender Therapy and Comparative Criminology

\title{
Gender Differences in Theory of Mind, Empathic Understanding, and Moral Reasoning in an Offending and a Matched Non-Offending Population
}




\begin{abstract}
Previous research suggests that a lack of pro-social skills is characteristic of an offending personality. Two hundred male and female offenders and matched controls completed measures to assess: Theory of Mind, empathic understanding, and moral reasoning. Significant differences between the offenders and the control group, as well as between the male and female participants, were detected in theory of mind, empathic understanding and moral reasoning with offenders scoring lower than the control group, and with males scoring lower than females on most tests. The ability to assess Theory of Mind, empathic understanding, and moral reasoning, and subsequently to identify reduced ability, is not only useful for researchers but will also allow practitioners to tailor existing (or develop new) interventions specific to the needs of individuals. This could be particularly useful in terms of recidivism when applied to those involved in anti-social or offending behaviour.
\end{abstract}

Key words: offenders; theory of mind; moral reasoning; empathy; gender 
Human behaviour is said to be underpinned by three individual cognitive abilities Theory of Mind (ToM; Premack \& Woodruff, 1978), empathic understanding (Davis, 1983), and moral reasoning (Gibbs et al., 1992). More recently, research has suggested an association between these skills (Spenser, Betts, \& Das Gupta, 2015) and that their combined utilisation allows for behavioural control (Ma, 2013; Shamay-Tsoory, 2011). As such, reduced abilities in these skills are thought to be associated with offending behaviours (Antonowicz \& Ross, 2005) and many rehabilitative interventions (aimed at reducing offending behaviours) have recognised the need to improve upon these skills (Palmer, 2013). However, a large number of interventions in the UK are grounded in male research (Lanctôt, 2018). Bottos (2007) proposed that this may be because women are involved in far fewer crimes than men, whilst Richardson and Hammock (2007) suggested it was more likely that the 'roles' traditionally assigned to women presented them with far less opportunity to indulge in offending behaviours. Yet, although in western society the 'roles' of women have become more like those of men, female offending patterns have not changed significantly (Estrada, Nilsson, \& Pettersson, 2019). Indeed, the Ministry of Justice continues to record a difference in male and female offending, with women being responsible for around $25 \%$ of crime in the UK (Criminal Justice Quarterly Update, 2017). This relatively low percentage, combined with the historic male focus of past research, means that many interventions (even those claiming to be gender-neutral) may not capture the specificities and complexities of the female offender (Belknap, Lynch, \& DeHart, 2016). This was also the view of the Corston Report (2007), which called for the development of more gender-responsive programmes and services for women involved in the Criminal Justice System.

Despite this lack of female focus, past research into ToM, empathic understanding, and moral reasoning has observed differences between genders. For example, Calero, Salles, Semelman, and Sigman (2013), in a study of 9- to 15-year-olds,F found that girls performed 
significantly better than boys in all ToM tasks. Similarly, Hiller, Young, and Weber (2014), using the five-step model of ToM (Peterson, Wellman, \& Liu, 2005), found that the young adult women demonstrated superior ability in ToM compared to young adult men, and that this ability was strongly associated with levels of prosociality. As such, it is claimed that women are better able to attribute the mental states of others, and affect more socially appropriate responses, than their male counterparts (Blair, 2005; Russell, Tchanturia, Rahman, \& Schmidt, 2007). In other words, it could be that women are more prosocially skilled than men, and therefore more compliant regarding the rules of society. If this is true, it is one reason why gender specific mediating variables should be considered before simply applying the causal theories surrounding male offending to female offending (Bennett, Farrington, \& Huesmann, 2005).

In addition, measurement of ToM has generally relied on methods that assess from a verbal perspective only. As research has shown that females typically perform better than males in most verbal tests, this may also explain why females are thought to have a better ToM when compared to males (Sagrilo \& Ferreira, 2012). Further, given that Blair and Coles (2000) reported that ToM requires the recognition and understanding not only of verbal cues but also visual cues (on which males typically perform better), any study assessing the construct using only verbal stimuli, may obtain findings that are biased towards female participants. Hence, to address this limitation, it is considered necessary when considering gender to employ measures that assess both verbal and visual ToM.

Regarding offending status, most prior studies have found no difference in ToM between offenders and non-offenders. For example, Dolan and Fulam (2004), using a battery of tasks to assess the ability of 89 male adult offenders (with either DSM IV antisocial personality disorder and/or psychopathic diagnoses), found that most of the participants had acquired an acceptable level of ToM. One explanation for the disparity between existing 
research and the perceived need for ToM based interventions for offenders, may be that such research has largely focused on the cognitive aspects of ToM; that is the ability to recognise the mental state of another person. However, Blair and Coles (2000) argued that to respond to another's mental state, an observer not only needs to recognise what another may be thinking but also to understand the mental state of that person. They noted that this requires affective ToM and may explain, at least in part, why many offenders typically 'pass' ToM tasks but are still poor at responding to another's mental state. In other words, an offender may recognise the thoughts another (e.g., fear or anger) but does not necessarily understand the implications of those thoughts. Therefore, to address these limitations a procedure which assesses the duality of ToM may well be required.

Research has also noted gender related ability in empathic understanding. For example, Messing, Randoin, Tissot, Rail, and Fortin (2004) demonstrated that the development of empathic understanding varied according to both the gender of the child, and of the parent. Noting the gender of both the participant and the parent, these researchers asked the children to complete an affective empathy measure, whilst their parent completed a scale to assess their own parenting style. A positive association between high levels of empathic understanding in female children and an 'empathic' child rearing style in their parent(s) was found; thus, suggesting that parenting style, as well as parent to child relationships, might play a significant role in the development of empathic understanding in children. Such a gender difference in empathic understanding appears to continue into young adulthood. With a sample of 60 male and female participants ( $M$ age $=24.5$ years), Rueckert, Branch, and Doan (2011) reported that the female participants scored significantly higher than the males on the Emotional Quotient (Baron-Cohen \& Wheelwright, 2004) and the Interpersonal Reactivity Index (Davis, 1980). However, one limitation of these studies may be that the measures used were self-report. Makino (2010) criticised self-report measures, 
suggesting that they might not be indicative of how a person feels but rather reflect their knowledge of how other people might expect them to feel. Therefore, Rueckert et al.'s findings may be a reflection of societally perceived 'gender roles', which suggest that women are more people-oriented, helpful, and empathic than men (Rueckert, Branch, \& Doan, 2011). Unlike ToM, differences in empathic understanding between offenders and nonoffenders have been more readily noted. For example, Bevan (2006), in a study of 106 adult male offenders (mean age of 33 years), found a significant association between reduced empathic understanding and offending behaviour. More specifically, Bevan noted that some offenders exhibited intolerance in response to the distress of their victims, whilst others demonstrated a level of excitement or enjoyment. This suggests that whilst the offenders were able to comprehend the emotional state of their victim, they lacked affective responses (e.g., shame or guilt) to those emotions (Blair, 2005). This may be explained by feelings of 'entitlement' (Raskin \& Terry, 1988); something historically associated with narcissism (Baskin-Sommers, Krusemark, \& Ronningstam, 2014). In practice, narcissism, coupled with a sense of entitlement, may 'give' an offender permission to disregard the law, as well as cause him or her to underestimate their chances of being caught when in pursuit of a personal goal (Hepper, Hart, Meek, Cisek, \& Sedikides, 2014). However, such findings are generally based on self-report measures of empathic understanding. Therefore, to better understand abilities in empathic understanding in male and female, offending and non-offending, populations, additional research using a performance-based measure is needed.

Lastly, regarding moral reasoning, implicit within Kohlberg's (1969) Stages of Moral Judgement is the belief that morality is equally applicable to men and women (Nisan \& Kohlberg, 1982). However, Kohlberg claimed that the average female attained a moral judgment rating of level three, whilst males reached an average of level four; thus, concluding that females are inferior to men in relation to moral reasoning. Gilligan (1982) 
questioned the validity of Kohlberg's claim, arguing that his reliance on a male normative sample resulted in both a theory and a measurement system that were insensitive to the traditional female concerns of responsibility and care. She noted that males tend to subscribe to a morality of rights or justice, whilst females value care, sensitivity, and responsibility to people, and only when both were integrated could moral reasoning be properly assessed. This was supported MacKinnon and Fiala (2015) who noted that some measures of moral reasoning were biased towards men. Consequently, a measure reflecting both care and justice orientations may be needed.

Further, some studies have found a strong negative relationship between moral reasoning and criminal behaviours. Kohlberg (1969, p. 33), for example, argued “...that children under nine, some adolescents, and adult criminals typically reasoned at stages one and two; whereas individuals who have achieved a higher level of moral reasoning engaged in responsible, consistent, and predictable behaviour". In a study of young male offenders ( $n$ $=60, M$ age $=19.53$ years, $S D=0.79)$ Palmer and Begum (2006) provided empirical support for this, finding that they reasoned in a way that maximised their own needs and desires, whilst minimising any negative consequences; thus, equating to Kohlberg's moral stage two. However, past research in this area has largely focused on young, male offenders and, as noted above, the prison estate nowadays includes a noteworthy proportion of female offenders and has no upper age limit; and so, to investigate differences in abilities in MR according to gender and offending status, a more representative age group is needed.

Therefore, to address the limitations identified in Spenser et al. (2015), and to better understand abilities in ToM, empathic understanding, and moral reasoning according to gender, as well an age representative offending status, the following study will include both male and female offenders and non-offenders, aged 18- to 55- years. The following 
hypotheses are made:

- Hypothesis 1 . There will be significant gender related differences in (a) verbal ToM, (b) visual ToM, (c) empathic understanding, and (d) moral reasoning.

- Hypothesis 2. There will be significant offending status related differences in (a) verbal ToM, (b) visual ToM, (b) empathic understanding, and (d) moral reasoning.

- Hypothesis 3. There will be an interaction between gender and offending status regarding (a) verbal ToM, (b) visual ToM, (c) empathic understanding, and (d) moral reasoning.

- Hypothesis 4. An association will be found between Verbal ToM and Visual ToM.

\section{Methodology}

A two-way, between groups, analysis of covariance (ANCOVA), controlling for both IQ and age, was conducted to explore the impact of gender and offending status on the four dependent variables: (i) verbal ToM; (ii) visual ToM; (iii) performance-based empathic understanding, and (v) moral reasoning. Lastly, associations between verbal and visual ToM using Pearson Product-Moment Correlation Coefficient were investigated.

\section{Participants.}

One hundred male offenders (aged 18 to 55 year-olds; $M=27.38, S D=7.095$ ) were recruited from a male adult prison in England and 100 female offenders (aged 18- to 55years; $M=30.24, S D=10.57$ ) were recruited from a female adult prison in England. Age matched controls of 100 males and 100 females were recruited from the general and student populations in England (aged 18 to 55 years; $M$ (male) $=27.89, S D=8.55$ and $M$ (female) $=$ $31.46, S D=10.78)$ who reported not having a criminal record. The samples were selfselected as all participants volunteered to take part; having responded to identical posters 
placed on either wing noticeboards in the prisons or prominent public places (such as libraries, community centre notice boards and the university intranet). As per the recruitment criteria, all participants were English speaking. Except for the student participants, who were given research credits for taking part, no other form of compensation was given to any of the participants.

\section{Measures.}

Participants completed four measures to assess ability in verbal and visual ToM, empathic understanding, and moral reasoning.

Verbal ToM: The Social Stories Questionnaire (SSQ, Lawson, Baron-Cohen, \& Wheelwright, 2004) was chosen to measure verbal ToM. This measure consists of ten vignettes, each divided into three sub-sections containing either: a blatantly offensive utterance, a subtly offence utterance, or no offensive utterance, which is made by one character to another. Participants were asked to tick 'yes' (and identify the dialogue line in which it appeared) if they thought a section contained an utterance which might upset or offend another character and 'no 'if they thought it was void of any offense. Participants were awarded one mark for each target utterance correctly identified, to a maximum of 30 marks. In the current study the internal consistency (Cronbach's alpha coefficient) was $\alpha=.72$.

Visual ToM: The 'Reading of the Mind in the Eyes test' revised version (BaronCohen et al., 2001) was chosen to measure visual ToM. This measure consists of 36 photographs (each of a face with only the eyes showing) split across 3 levels: 12 positive emotions, 12 negative emotions, and 12 neutral emotions. Four words were associated with each set of eyes and participants were asked to pick the one they thought best described what the person in the photograph was thinking or feeling; only one was deemed to be 'correct'. In the current study the internal consistency was $\alpha=.61$. 
Performance-Based Empathic Understanding. The Emotional Intelligence Test (MSCEIT; Mayer, Salovey, \& Caruso, 2002) was chosen to assess performance-based empathic understanding. This assesses the four-branch model of emotional intelligence (perceiving emotions, using emotions, understanding emotions, and regulating emotions). It consists of 141 questions that are divided among 8 tasks (2 for each branch). Participants received credit for correct answers. In the current study the internal consistency was $\alpha=.76$.

Moral Reasoning. The Socio-Moral Reflection Measure (SRM-SF, Gibbs, Basinger, Fuller, \& Fuller, 1992) assessed participants' moral judgment, including contract, affiliation, life, property, law, and legal justice. Participants noted the level of importance they attributed to each of 11 statements (e.g., "Do you think that the truth should be told at all times?") using a three-point scale (very important, important, and not important). They were then asked to give a short reason as to why they had attributed that level of importance to an item. Participants were awarded credit according to their answer. The measure has been found, in past research, to discriminate between offenders and non-offenders (Palmer \& Begum, 2006). In the current study the internal consistency was $\alpha=.93$.

Written consent was obtained from all participants in line with both the National Offenders Management Services (NOMS) and the University's ethical approval procedure. Participants in both the offender and control groups were tested individually in an empty room in either the prison or university. The lead author sat in the room with the participant to provide help with reading the stories or statements if required. When no help was needed, she remained silent, out of the participant's direct line of vision, and at a suitable distance to protect the participant's privacy. In the offender group the door to the room remained open at all times and a prison officer was stationed outside the room to ensure safety; the officer was not in the participant's direct line of vision and a suitable distance was maintained to protect the participant's privacy. Each participant was given standard verbal instructions and told 
that the session was not timed but should be completed as quickly as possible. The presentation of the measures was counterbalanced to control for order effects.

\section{Results.}

The mean scores and the $S D$ indicated that all the scores were located close to the relevant mean (Table 1).

Insert Table 1 approximately here.

Testing was then conducted to check for normality, linearity, univariate and multivariate outliers, homogeneity of variance-covariance matrices and multicollinearity. The Kolmogorov-Smirnov procedure was used to assess the distribution of the scores. For each of the dependent measures the results indicated violation of the assumption of normality. However, the box plots indicated the existence of a small number of outliers which may have been the cause of the violation. The normal Q-Q plots for each of the dependent measures produced reasonably straight lines in each case, suggesting a near normal distribution. Therefore, it was decided to reject the option of transformation. However, as Levene's Test of Equality of Error Variances indicated that the assumption of equality of variance had been violated for each of the measures, $p>.05$, and after following Tabachnick and Fidell's recommendations (2013), a more stringent value of $p$ was adopted, $p<.025$.

A series of two-way, between groups ANCOVA (controlling for age and IQ), was conducted to explore the impact of gender and status on the four dependant variables.

Verbal ToM: Hypothesis 1a was supported as there was a significant main effect of gender, $F_{(5,394)}=106.075, p=.000$. The effect size was small (partial eta squared $=.212$. Post-hoc comparisons using Tukey's HSD test indicated that the scores for the male group ( $M$ 
$=9.75, S D=5.35)$ were lower than the female group $(M=14.38, S D=4.66$. Similarly, hypothesis 2 a was supported as there was a significant main effect of offending status, $F_{(5,}$ 394) $=69.921, p=.000$. The effect size was small (partial eta squared $=.151)$. Post-hoc comparisons using Tukey's HSD test indicated that the scores for the offender group ( $M$ $=10.32, S D=6.09)$ were lower than the non-offender group $(M=13.81, S D=4.25)$. Hypothesis 3a was partially supported as there was a statistically significant interaction between gender and offending status, $F_{(5,394)}=61.236, p=.000$. However, it was found that verbal ToM was dependant on offending status for males, but for females this was not case.

Visual ToM: Hypothesis $1 \mathrm{~b}$ was not supported as there was no significant main effect of gender, $F_{(5,394)}=4.578, p=.033$. The effect size was small (partial eta squared $\left.=.011\right)$. In contrast, hypothesis $2 \mathrm{~b}$ was supported as there was a significant main effect of offending status, $F_{(5,394)}=69.921, p<.001$; the effect size was medium (partial eta squared $=.322$ ). Post-hoc comparisons using Tukey's HSD test indicated that the for the offender group ( $M$ $=19.16, S D=8.04)$ were lower than the non-offender group $(M=28.9, S D=8.26$. Hypothesis $3 \mathrm{~b}$ was not supported as the interaction between gender and offending status was not significant $F_{(5,394)}=.547, p=.46$.

Verbal and Visual ToM: The relationship between verbal ToM and visual ToM was investigated using Pearson's product-moment correlation coefficient. Hypothesis 4 was supported as there was a moderate relationship between the two variables, $r(398)=.522, p=$ .000 .

Empathic Understanding: Hypothesis 1c was supported as there was a significant main effect of gender, $F_{(5,394)}=47.783, p<.00$. The effect size was small (partial eta squared $=.108)$. Post-hoc comparisons using Tukey's HSD test indicated that the scores for the male group $(M=115.12, S D=24.89)$ were lower than the female group $(M=129.40, S D$ $=20.70$ ). Hypothesis $2 \mathrm{c}$ was also supported as there was a main effect of offending status, $F$ 
$(5,394)=80.183, p<.001$. The effect size was small $($ partial eta squared $=.169)$. Post-hoc comparisons using Tukey's HSD test indicated that the scores for the offender group $(M=$ $113.67, S D=21.80)$ were lower than the non-offender group $(M=130.85, S D=20.97)$. Hypothesis $3 \mathrm{c}$ was also supported as the interaction was significant, $F_{(5,394)}=11.367, p=$ .001 .

Moral Reasoning: Hypothesis 1d was not supported as the effect of gender was not significant, $F_{(5,394)}=3.299, p=.07$. However, hypothesis $2 \mathrm{~d}$ was supported as there was a significant main effect of status, $F_{(5,394)}=262.853, p<.001$. The effect size was medium (partial eta squared $=.400$ ). Post-hoc comparisons using Tukey's HSD test indicated that the scores for the offender group $(M=274.75, S D=33.95)$ was lower than the non-offender group $(M=325.15, S D=27.17)$. Hypothesis $3 \mathrm{~d}$ was not supported as the interaction effect between gender and status was not statistically significant, $F_{(5,394)}=1.352, p=.246$.

\section{Discussion.}

The current study examined possible effects of gender and offending status on ToM, empathic understanding, and moral reasoning across a representative age range.

Verbal ToM: By using a 'Faux Pas' task that simultaneously assessed both cognitive and affective ToM, the present study adds to the literature by finding, in a single study, an effect of gender, with the males scoring lower on verbal ToM than the females. This might be explained by considering variations in the amount of supportive and emotional talk that parents and older siblings have with younger children, with such communications favouring girls over boys (Brown \& Dunn, 1996). According to Leaper, Anderson, and Sanders (1998), this may be all that is needed to give girls an advantage over their male counterparts regarding their developing ToM. Similarly, Hughes (1998) proposed that parents may 'train' 
female offspring to think more carefully than males about social interactions, by making the thoughts, beliefs, and feelings of others the focus of discussions.

The present study also importantly differs from most past research in that it found an effect of offending status; with the offenders scoring lower on verbal ToM than the nonoffenders. One explanation for this difference from prior work may relate to the traditional methods used to assess ToM. Richell et al. (2003), for example, used a measure that considered only emotional recognition and not both emotional recognition and understanding; Shamay-Tsoory et al. (2005) suggested that Richell et al.'s study was an assessment of cognitive ToM and not cognitive and affective ToM. Blair and Coles (2000) stated that both cognitive and affective ToM are needed for the recognition and understanding of another person's cues, this may explain why offenders typically 'pass' ToM tasks but are still poor at responding to another's mental state. Further, the main aim of Richell et al. (2003) was to compare abilities in ToM between two offender groups; a psychopathic group and a nonpsychopathic group, and not to identify differences in ability in ToM between offenders and non-offenders. Therefore, it could be that both offender groups (the psychopath and the nonpsychopath) had similar, possibly reduced, abilities in ToM.

Visual ToM: The current study did not find a significant effect of gender on visual ToM. However, it did find an effect on visual ToM of offending status, with the offender group scoring lower than the non-offender group. Regarding gender, Bolger, Hornickel, Cone, Burman and Booth (2007) noted that boys appear to outperform girls in tasks where they are presented with a visual stimulus; whilst girls outperform boys in tasks where there is a verbal stimulus. Using Functional Magnetic Resonance Imaging they measured the brain activity in 31 boys and 31 girls (aged 9 to 15 years) as they performed spelling and writing tasks delivered in two sensory modalities: verbal and visual. Burman and Booth also found that the boys showed significantly greater activation in the language areas of the brain, when 
presented with a visual stimulus, when compared to the girls. The reverse was also true in that the girls outperformed the boys when the stimulus was delivered by means of the written word. The present study used 'Reading the Mind in the Eyes' test (Baron-Cohen et al., 2001) that involves looking at photographs of eyes whilst simultaneously matching the observed expressions to one of the four written descriptors. Consequently, the measure assessed both verbal and visual stimuli. As such, it is possible that the differing stimuli compensated for each other and future research may wish to identify a task that bypasses language and assesses ToM in a purely visual manner; thus, reducing the number of executive demands placed upon the participant (Roux \& Uhlhaas, 2014).

Regarding the effect of offending status on visual ToM, one explanation may be that delayed cognitive development, possibly caused by a background where abuse, conflict, neglect, and negative attitudes predominate (Towl \& Crighton, 2010), may have an impact on ToM (Happé \& Frith, 1996). Keenan and Ward (2000) noted that individual experiences within the family, and/or larger social environments, are experienced from both a verbal and a visual standpoint. Schurz et al. (2015), stated that visual perspective taking is a fundamental feature of the human social brain, and aids a more accurate representation. Therefore, it could be contended that a delayed or reduced development in relation to ToM might feasibly affect both verbal and visual perspective taking. To the current authors' knowledge, the present study is the first to demonstrate an effect of offending status in visual ToM.

Empathic Understanding: The current study found a significant effect of gender for performance-based empathic understanding with the female group scoring higher than the male group, and an effect of offending status on performance-based empathic understanding with the offender group scoring lower than the non-offender group. In addition, a significant interaction was found. One possible explanation for the effect of gender may be attributed to levels of the hormone testosterone. Whilst, testosterone is responsible for the development of 
male gender characteristics, it has also been linked to reduced empathy in both genders (Batrinos, 2012). For example, Harris, Rushton, Hampson, and Jackson (1996), with a sample of 155 male and 151 female participants, found that a lower level of testosterone acted as a predictor of empathic understanding measure in men and women. However, although testosterone is found in both men and women, men have approximately ten times as much of the hormone as their female counterparts. So, it might be contended that men will be less empathic than women (Baron-Cohen, 2002). Considering this, Hermans, Ramsey, and van Honk (2008) examined the association between testosterone levels and emotional mimicry (the ability to mimic the thoughts, beliefs, and feelings of another person). They found that a single dose of testosterone was enough to significantly decrease emotional mimicry in the female participants which led Hermans et al. to conclude that the naturally higher baseline of testosterone in males could be an explanation for their reduced ability to mimic emotions.

The present study also found that the offender group scored lower than the nonoffender group on performance-based empathic understanding. Whilst this is in keeping with past research, historically studies considering empathic understanding have relied on selfreport measures (Blair, 2005). As mentioned above, such tests may be influenced by demand characteristics (Makino, 2010). Therefore, by using a performance-based measure, that may result in a truer realisation of abilities in empathic understanding, the present study adds to the literature.

Moral Reasoning: No main effect according to gender was found in the present study; however, a main effect according to status was found; with the offender group scoring lower than the non-offender group on measures for moral reasoning. The present study addresses the existing controversy regarding gender moderated moral reasoning. For example, Gilligan (1982) asserted that women tend to resolve moral dilemmas using a care approach, whilst men tend to use a justice approach. However, Clopton and Sorell (1993) suggested that such 
differences may be due to the various types of dilemmas women and men encounter in their daily lives, rather than to the way in which men or women might approach a problem. To address this issue, Clopton and Sorell restricted the types of dilemma used in their study to those relating to parenting. Using this type of dilemma, they found that men and women did not differ in their use of care or justice reasoning when the dilemma type was restricted; thus, supporting the conclusion that male and female differences in moral reasoning probably result from differences in circumstances rather than from gender characteristics. Friesdorf, Conway, and Gawronski (2015), following their meta-analysis of 40 studies, in which the 6100 male and female participants were asked a number of questions posing various moral dilemmas (including decisions about murder, torture, lying, abortion, and animal research) noted that differences in gender related morality were due to women having a stronger emotional aversion to harmful actions, rather than an actual difference in cognitive reasoning abilities, when compared to men. Further, Friesdorf et al. suggested that these studies, in assuming that moral behaviour is dependent on affective processes, often ignored the consequences of actions. So, by using less emotive dilemmas (and thus controlling for emotions), they proposed that no evidence for gender differences might be found. Therefore, by using a gender-neutral assessment of moral reasoning the present study adds importantly to the literature, finding an effect for moral reasoning according to offending status with the offenders achieving lower on the measure for moral reasoning than the non-offenders. In the context of Kohlberg's theory, the present findings revealed that offenders, on average, reached Stage 2, whilst the non-offenders were found to reason at Stage 3. Although such a finding was identified by Palmer and Begum (2006), their study considered only adolescent offenders. In contrast, the participants in the current study ranged from 18 to 55 year of age; thus, addressing a more representative age group in terms of the prison estate, and so adding to the literature. 
Interaction between gender and offending status: With regard to any interaction between gender and offending status, the results varied according to the outcome measured. For visual ToM and moral reasoning, no significance was found. Regarding verbal ToM, significance was found for male participants only. However, significance was found for all groups regarding empathic understanding.

The findings relating to empathic understanding may be reflective of the measure adopted. Makino (2010) suggested that the traditional method of assessing empathetic understanding (e.g., using a self-report measure) may not be representative of how a participant actually feels, but rather reflect his or her beliefs relating to how society expects them to feel. An example of this was found by Klein and Hodges (2001) who noted that when the participants were told the true nature of the study, no gender differences were identified in empathic understanding. However, the women in their study scored more highly than the men when the reasons for the research were withheld. Therefore, it may be that the interaction between gender and offending status relating to empathic understanding as identified by the performance-based measure used in the present study, are a truer reflection of ability; something that could be further differentiated by offending status.

Language development may offer one explanation as to why an interaction between gender and offending status, in relation to verbal ToM, was found only in the male groups. Findings have suggested that men are less lingually advanced than their female counterparts (Wallentin, 2020), which is said to be further exaggerated by offending status (Winstanley, Webb, \& Conti-Ramsden, 2019). Apperly and Butterfill (2009), and more recently Meinhardt-Injac, Daum, Meinhardt and Persike (2018), noted that reflexive-cognitive processes (language) is required to understand the mental state of another person. Thus, differing abilities in language may account for the present findings. 
Lastly, when considering the non-significant findings relating to visual ToM and moral reasoning, one explanation may be found in cognitive flexibility and inhibitory control. Cognitive flexibility allows a person to make simultaneous judgments, from multiple and sequentially shifting situations, and so 'make sense' of everyday interactions, whilst inhibitory control allows the individual to supress his or her own immediate responses long enough to allow for a considered response (Spenser, Bull, Betts \& Winder, 2019). Research suggests that both are closely associated with personality (Odacı \& Cikrikci, 2019). Personality is said to be influenced by heredity, environment, and situation (Hopwood et al., 2011), which may include, but is not limited to, gender and offending status. Therefore, the omission of other factors, beyond gender and offending status, may go some way to explain the findings in the present study. Nevertheless, these findings do lend some support to the proposal that male offending and female offending is mediated by a number of different factors that can differ across gender.

To summarise, differences in perspective taking and decision making according to offending status have been of interest to researchers for several years; specifically, in the context of reducing offending levels through rehabilitative programmes (Vessels \& Huitt, 2005). Whilst the current study was not without limitations; specifically, it did not differentiate between crime categories, measure individuals serving sentences of more than six months or include those with community disposals (something future studies may wish to address), to the knowledge of the authors it is first to examine for differences in ToM, empathic understanding, and moral reasoning, in a sample of both male and female, offenders and non-offenders, across a representative age group, in a single study. As a result, the conclusion that offenders may differ in their abilities regarding ToM, empathic understanding, and moral reasoning when compared to a matched group of non-offenders, 
and that male offenders may differ in their abilities regarding verbal ToM and performancebased empathic understanding when compared to female offenders, adds to the literature.

Finally, the current authors suggest that to maximise the success of interventions aimed at reducing offending behaviours by improving prosocial abilities, assessment of individuals' abilities in ToM, empathic understanding, and moral reasoning may well be of benefit. That is, if offenders score below the established norm in measures for these skills it may not be unreasonable to expect that he or she may benefit from an intervention aimed at improving prosocial abilities. In addition, and perhaps most pertinently, if and when reduced abilities in ToM, empathic understanding, and / or moral reasoning are identified, practitioners may wish to group individuals with similar abilities together and / or tailor interventions to meet the specific needs of that sample. Overall, it is posited that consideration of these factors may be of benefit in terms of reducing levels of recidivism in the UK and beyond. 


\section{References}

Adler, F. (1975). Sisters in Crime: The Rise of the New Female Criminal. New York: McGraw-Hill.

Antonowicz, D. H., \& Ross, R. R. (2005). Social problem-solving deficits in offenders. In M. McMurran \& J. McGuire (Eds.), Social problem-solving and offending: Evidence, evaluation and evolution, (p. 91-102). Chichester, England: John Wiley \& Sons.

Apperly, I. A., \& Butterfill, S. A. (2009). Do humans have two systems to track beliefs and belief-like states? Psychological Review, 116(4), 953-970. https://doi.org/10.1037/a0016923

Baron-Cohen, S. (2002). The extreme male brain theory of autism. Trends in Cognitive Sciences, 6, 248-254. https://doi.org/10.1016/s1364-6613(02)01904-6

Baron-Cohen, S, Wheelwright, S, Hill, J, Raste, Y, \& Plumb, I, (2001). The 'Reading the Mind in the Eyes' test revised version: a study with normal adults, and adults with Asperger Syndrome or high-functioning autism. Journal of Child Psychiatry and Psychiatry, 42, 241-252

Baron-Cohen, S, \& Wheelwright, S. (2004) The Empathy Quotient: an investigation of adults with Asperger Syndrome or high functioning autism, and normal sex differences. Journal of Autism and Developmental Disorders, 34, 163- 175. https://doi.org/10.1023/B:JADD.0000022607.19833.00

Baskin-Sommers, A., Krusemark, E., \& Ronningstam, E. (2014). Empathy in narcissistic personality disorder: From clinical and empirical perspectives. Personality Disorder: Theory, Research and Treatment, 5(3), 323-333. https://doi.org/10.1037/per0000061

Batrinos, M. L. (2012). Testosterone and aggressive behaviour in man. International 
Journal of Endocrinology \& Metabolism, 10(3), 563-568.

https://doi.org/10.5812/ijem.3661

Belknap, J, Ly.nch, S., \& DeHart, D. (2016). Jail Staff Members' Views on Jailed Women's Mental Health, Trauma, Offending, Rehabilitation, and Re-entry. Prison Journal, 96, 79-101. https://doi.org/10.1177/0032885515605485

Bennett, S., Farrington, D.P., \& Huesmann, L.R. (2005). Explaining gender differences in crime and violence: The importance of social cognitive skills. Aggression and Violent Behavior, 10, 263-288. https://doi.org/10.1016/j.avb.2004.07.001

Beven, S. (2006). Interpersonal emotional responses in violent offenders: (Re) examining the role of empathy. School of Law. Murdoch University: Western Australia.

Blair, R.J.R. (2005). Applying a cognitive neuroscience perspective to the disorder of psychopathy. Development and Psychopathology, 17(03), 865-891. https://doi.org/10.1017/S0954579405050418.

Blair, R.J.R., \& Coles, M. (2000). Expression recognition and behavioural problems in early adolescence. Cognitive Development, 15, 421-434.

https://doi.org/10.1016/S0885-2014(01)000039-9.

Bolger, D.J., Hornickel, J., Cone, N.E., Burman, D.D., \& Booth, J.R. (2007). Neural correlates of orthographic and phonological consistency effects in children. Human Brain Mapping, 29(12), 1416-29. https://doi.org/10.1002/hbm.20476

Bottos, S. (2007). Women and violence: Theory, risk and treatment implications. Research report no. R-198. Ottawa, ON, Canada: Research Brand Correctional Service Canada.

Brackett, M.A. \& Mayer, J.D. (2003). Convergent, discriminant and incremental validity of competing measures of emotional intelligence. Personality and Social Psychology Bulletin, 29, 1147-1158. https://doi.org/10.1177/0146167203254596 
Brown, J. R., \& Dunn, J. (1996). Continuities in emotion understanding from three to six years. Child Development, 67(3), 789-803. https://doi.org/10.2307/1131861

Calero, C.I., Salles, A., Semelman, M., \& Sigman, M. (2013). Age and gender dependent development of Theory of Mind in 6- to 8-years old children. Frontiers in Human Neuroscience, 7, 281. https://doi.org/10.3389/fnhum.2013.00281

Colby, A., \& Kohlberg, L. (1987). The Measurement of Moral Judgment Vol. 2: Standard Issue Scoring Manual. Cambridge University Press.

Clopton, N. A., \& Sorell, G. T. (1993). Gender differences in moral reasoning: Stable or situational? Psychology of Women Quarterly, 17, 85-102. https://doi.org/10.1111/j.1471-6402.1993.tb00678.x

Corston, J. (2007). The Corston Report: a review of women with particular vulnerabilities in the criminal justice system. London: Home Office.

Davis, M.H. (1980). A multidimensional approach to individual differences in empathy. Catalogue of Selected Documents in Psychology, 10, 85.

Davis, M. H. (1983). Measuring individual differences in empathy: Evidence for a multidimensional approach. Journal of Personality and Social Psychology 44(1), 113-126. https://doi.org/10.1037/0022-3514.44.1.113

Dolan, M., \& Fulam, R. (2004). Theory of mind and mentalising ability in antisocial personality disorders with and without psychopathy. Journal of Moral Education, 27(3), 371-391. https://doi.org/10.1017/S0033291704002028

Estrada, F., Nilsson, A., \& Pettersson, T. (2019) The female offender - A century of registered crime and daily press reporting on women's crime. Nordic Journal of Criminology, 20(2), 138-156. https://doi.org/10.1080/2578983X.2019.1657269

Friesdorf, R., Conway, P., \& Gawronski, B. (2015). Gender Differences in Responses to Moral Dilemmas: A Process Dissociation Analysis. Personality and Social 
Psychology Bulletin, 41(5), 696-713. https://doi.org/10.1177/0146167215575731

Gächter, S. Nosenzo, D., \& Sefton, M. (2012). The impact of social comparisons on reciprocity. The Scandinavian Journal of Economics, 114, 1346-1367. https://doi.org/10.1111/j.1467-9442.2012.01730.x

Gibbs, J. C., Basinger, K.S., Fuller, D., \& Fulkler, R.L. (1992). Moral maturity: measuring the development of sociomoral reflection. New Jersey: Lawrence Erlbaum Associates. Inc.

Gilligan, C. (1982). In a different voice: psychological theory and women's development. Cambridge, MA: Harvard University Press.

Happé, F.G.E., \& Frith, U. (1996). Theory of mind and social impairment in children with conduct disorders. British Journal of Developmental Psychology, 14(4), 385-398. https://doi.org/10.1007/s10803-005-0039-0

Harris, J. A., Rushton, J. P., Hampson, E., \& Jackson, D. N. (1996). Salivary testosterone and self-report aggressive and pro-social personality characteristics in men and women. Aggressive Behavior, 22, 321-331. https://doi.org/10.1002/(SICI)1098$\underline{2337(1996) 22: 5<321:: A I D-A B 1>3.0 . C O ; 2-M}$

Hepper, E. G., Hart, C. M., Meek, R., Cisek, S. Z., \& Sedikides, C. (2014). Narcissism and empathy in young offenders and non-offenders. European Journal of Personality, 28, 201-210. https://doi.org/10.1002/per.1939

Hermans, E. J., Ramsey, N. F., \& van Honk, J. (2008). Exogenous testosterone enhances responsiveness to social threat in the neural circuitry of social aggression in humans. Biological Psychiatry, 63, 263-270. https://doi.org/10.1016/j.biopsych.2007.05.013

Hiller, R. M., Young, R. L., \& Weber, N. (2014). Sex differences in autism spectrum disorder based on DSM-5: evidence from clinician and teacher reporting. Journal of 
Abnormal Child Psychology, 42(8), 1381-1393. https://doi.org/10.1007/s10802-014$\underline{9881-\mathrm{X}}$

Hopwood, C.J., Donnellan, M.B., Blonigen, D.M., Krueger, R.F., McGue, M., Iacono, W.G., \& Burtet, S.A. (2011). Genetic and environmental influences on personality trait stability and growth during the transition to adulthood: a three-wave longitudinal study. Journal of Personality and Social Psychology, 100(3), 545-556. https://doi:10.1037/a0022409

Hughes, C. (1998). Executive function in pre-schoolers: Links with theory of mind and verbal ability. British Journal of Developmental Psychology, 16, 233-253. https://doi.org/10.1111/j.2044-835X.1998.tb00921.x

Keenan, T., \& Ward, T. (2000). A theory of mind perspective on cognitive, affective, and intimacy deficits in child sexual offenders. Sexual Abuse: A Journal of Research and Treatment, 12, 49-58. https://doi.org/10.1023/A:1009563821140

Klein, K.J.K. \& Hodges, S.D. (2001). Gender differences, motivation, and empathic accuracy: When it pays to understand. Personality and Social Psychology Bulletin, 27, 720-730. https://doi.org/10.1177/0146167201276007

Kohlberg, L. (1969). Stage and sequence: The cognitive-developmental approach to socialization. In D. Goslin (Ed.) Handbook of socialization theory and research (pp. 347-480). Chicago, IL: Rand McNally.

Lanctôt, N. (2018). Gender-Responsive Programs and Services for Girls in Residential Centers: Meeting Different Profiles of Rehabilitation. Criminal Justice and Behaviour, 45(1), 101 - 120. https://doi.org/10.1177/0093854817733495

Lawson, J., Baron-Cohen, S., \& Wheelwright, S. (2004). Empathising and Systemising in adults with and without Asperger's Syndrome. Journal of 
Autism and Developmental Disorders, 34, 301-310.

https://doi.org/10.1023/b:jadd.0000029552.42724.1b

Leaper, C., Anderson, K. J., \& Sanders, P. (1998). Moderators of gender effects on parents' talk to their children: a meta-analysis. Developmental Psychology, 34, 3 - 27. https://doi.org/10.1037/0012-1649.34.1.3

MacKinnon, B., \& Fiala, A. (2015). Ethics: Theory and contemporary issues ( $8^{\text {th }}$ ed.). Stamford, CT: Cengage.

Makino, H. (2010). The development of a new performance-based test for measuring emotional intelligence: Humanity-Empathy-Assertiveness-Respect Test. Unpublished doctoral thesis. Retrieved from UMI Dissertation Publishing. (UMI Number: 3409390).

Ma, H. K. (2013). The Moral Development of the Child: An Integrated Model. Frontiers in Public Health, 1, 57 https://doi.org/10.3389/fpubh.2013.00057

Mayer, J. D., Salovey, P., \& Caruso, D. R. (2002). Mayer-Salovey-Caruso emotional intelligence test (MSCEIT) user's manual. Toronto, Canada: Multi-Health Systems.

Meinhardt-Injac, B., Daum, M. M., Meinhardt, G., \& Persike, M. (2018). The two-systems account of theory of mind: Testing the links to social-perceptual and cognitive abilities. Frontiers in Human Neuroscience, 12 (25).

https://doi.org/10.3389/fnhum.2018.00025

Messing, K., Randoin, M., Tissot, F., Rail, G., \& Fortin, S. (2004). Unnecessary suffering: posture Static standing in service jobs. Labour, Gender and Societies, 12, 77-104.

Ministry of Justice. (2017). Criminal Justice Statistics, Quarterly Update to September 2017. London: Ministry of Justice. 
Nisan, M., \& Kohlberg, L. (1982). Universality and variation in moral judgment: A longitudinal and cross-sectional study in Turkey. Child Development, 53, 865-876. https://doi.org/10.2307/1129123

Odacı, H., \& Cikrikci, Ö. (2019). Cognitive Flexibility Mediates the Relationship between Big Five Personality Traits and Life Satisfaction. Applied Research Quality Life, 14, 1229-1246. https://doi.org/10.1007/s11482-018-9651-y

Palmer, E. (2013). Offending Behaviour. Routledge. ISBN1135995311, 9781135995317

Palmer, E.J., \& Begun, A. (2006). The relationship between moral reasoning, provictim attitude and interpersonal aggression among imprisoned young offenders. International journal of offending theory and comparative criminology, 50(4), 446457.

Peterson, C. C., Wellman, H. M., \& Lui, D. (2005). Steps in theory of mind development for children with deafness or autism. Child Development, 76(2), 502-517.

Premack, D., \& Woodruff, G. (1978). Does the chimpanzee have a theory of mind? Behavioural and Brain Sciences, 1, 515-526. https://doi.org/10.1017/S0140525X00076512

Raskin, R., \& Terry, H. (1988). A principal-components analysis of the Narcissistic Personality Inventory and further evidence of its construct validity. Journal of Personality and Social Psychology, 54, 890-902. http://dx.doi.org/10.1037/0022$\underline{3514.54 .5 .890}$

Richardson, D.S. \& Hammock, G.S. (2007). Social context of human aggression: Are we paying too much attention to gender? Aggression and Violent Behavior, 12, 417426. https://doi.org/10.1016/j.avb.2006.11.001

Richell, R.A., Mitchell, D. G.V., Newman, C., Leonard, A., Baron- Cohen, S., \& 
Blair, R.J.R. (2003). Theory of the mind and psychopathy: can psychopathic individuals read the 'language of the eyes. Neurospychologia, 41, 523-526. https://doi.org/10.1016/S0028-3932(02)00175-6

Roux, F., \& Uhlhaas, P. J. (2014). Working memory and neural oscillations: alpha-gamma versus theta-gamma codes for distinct WM information? Trends in Cognitive Science, 18, 16-25. https://doi.org/10.1016/j.tics.2013.10.010

Rueckert, L., Branch, B., \& Doan, T. (2011). Are Gender Differences in Empathy Due to Differences in Emotional Reactivity? Psychology, 02(06), 574-578. https://doi.org/10.4236/psych.2011.26088

Russell, T. A., Tchanturia, K., Rahman, Q., \& Schmidt, U. (2007). Sex differences in Theory of Mind: A male advantage on Happe's "cartoon" task. Cognition and Emotion, 21(7), 1554-1564. https://doi.org/10.1080/02699930601117096

Sagrilo, M.C. P., \& Ferreira, T.L. (2012). Difference between auditory and visual span in genders: Pilot study. Revista CEFAC, 15, 552-560.

Schurz, M., Kronbichler, M., Weissengruber, S., Surtees, A., Samson, D., \& Perner, J. (2015). Clarifying the role of theory of mind areas during visual perspective taking: Issues of spontaneity and domain-specificity. NeuroImage, 117, 386-96 https://doi.org/10.1016/j.neuroimage.2015.04.031.

Shamay-Tsoory, S.G. (2011). The neural bases for empathy. The Neuroscientist, 17 (1), 18-24. https://doi.org/10.1177/1073858410379268

Shamay-Tsoory, S.G., Tomer, R., Aharon-Peretz, J. (2005). The neuroanatomical basis of understanding sarcasm and its relationship to social cognition. Neuropsychology, 19(3), 288-300. https://doi.org/10.1037/0894-4105.19.3.288 
Spenser, K. A., Betts, L. R., \& Das Gupta, M. (2015). Deficits in Prosocial Skills: A comparison between young-adult offenders and non-offenders. Psychology, Crime and Law, 21(7), 632-647. https://doi.org/10.1080/1066316x.2015.1028542.

Spenser, K.A., Bull, R., Betts, L., \& Winder, B. (2019). Executive functioning as a predictive measure of offending behaviour. Journal of Criminal Psychology, 9(1), 10-22. https://doi:10.1108/JCP-07-2018-0032

Tabachnick, B. G., \& Fidell, L. S. (2013). Using multivariate statistics, 6th ed. Boston: Pearson.

Towl, G.J. \& Crighton, D.A. (2010). Forensic Psychology. Wiley-Blackwell. ISBN: 978-1-4443-1930-9.

Vessels, G., \& Huitt, W. (2005). Moral and character development. Paper presented at the National Youth at Risk Conference, Savannah, GA, June 8-10.

Wallentin, M. (2020). Gender differences in language are small but matter for disorders, In R. Lanzenberger, G.S. Kranz, \& I Savic (Eds.), Handbook of Clinical Neurology, (Volume 175, p. 81-102). England: Elsevier. https://doi.org/10.1016/B978-0-44464123-6.00007-2.

Ward, T., Keenan, T., \& Hudson, S.M. (1999). Understanding cognitive, affective, and intimacy deficits in sexual offenders: A developmental perspective. Aggression and Violent Behaviour, 5, 41-62. https://doi.org/10.1016/S1359-1789(98)00025-1

Winstanley, M., Webb, R.T., \& Conti-Ramsden, G. (2019). Psycholinguistic and socioemotional characteristics of young offenders: Do language abilities and gender matter? Legal and Criminological Psychology, 3, 1-11.

https://doi.org/10.1111/lcrp.12150 